\title{
Solution to the absinthe challenge
}

\section{Lucia D'Ulivo}

(C) Springer-Verlag Berlin Heidelberg 2014

The winner of the absinthe challenge (published in volume 406, issue 7) is:

Jan Bernhammer, National University of Singapore, Singapore

The award entitles the winner to select a Springer book of his choice up to a value of $€ 100$.

Our congratulations!

In the early 20th century, absinthe was unjustly accused of causing the so-called absinthism syndrome. Nowadays, we know that the thujone content of absinthe was substantially overestimated, because of the crude analytical techniques of that period. Curiously, Dalmatian sage, a flavoring herb commonly found in kitchens, contains more than $50 \%$ thujone in its oil [1]. Despite that, no one has yet banned sage from the pantry!

Like many other spirits of its kind (for example Greek ouzo, Italian sambuca, or French pastis), absinthe is a herbal distillate containing essential oils [2]. A variety of compounds, for example the monoterpene thujone and the aromatic compound anethol, are dissolved in these oils and contribute to the complex taste of the drink. The compounds dissolved in the essential oils are highly soluble in alcohol but not so in water. Consequently, when cold water is added

This article is the solution to the Analytical Challenge to be found at http://dx.doi.org/10.1007/s00216-013-7576-8

L. D’Ulivo $(\square)$

57 Heney Street, Ottawa, ON K1N 5V7, Canada

e-mail: lucia.dulivo@gmail.com to the spirit, the alcohol is progressively diluted and the essential oils are eventually forced out of solution. However, for specific proportions of oils, alcohol, and water, we observe the formation of a stable dispersed system, also known as a microemulsion [3]. The metastable region of the system is defined by the area delimited by the binodal and spinodal curves of the phase diagram [4]. This liquidliquid dispersion contains heterogeneities of size comparable with the wavelength of visible light. These scatter the light in all directions, creating the milky appearance of the liquid [5].

Because these types of microemulsion are metastatic systems, their stability can decrease rapidly with small variations of the physical conditions. Specifically, increasing the temperature leads to growth of the dispersed oil droplets, with consequent deterioration of the emulsion [5]. Therefore, diluting absinthe with cold water will ensure the stability of the microemulsion whereas use of warm water might cause unpleasant phase-separation effects that could make the absinthe drink less enjoyable.

\section{References}

1. Perry NB, Anderson RE, Brennan NJ, Douglas MH, Heaney AJ, McGimpsey JA, Smallfield BM (1999) J Agric Food Chem 47: 2048-2054

2. Lachenmeier DW, Walch SG, Padosch SA, Kröner LU (2006) Crit Rev Food Sci Nutr 46:365-377

3. Sitnikova NL, Sprik R, Wegdam G (2005) Langmuir 21:7083-7089

4. Vitale SA, Katz JL (2003) Langmuir 19:4105-4110

5. Grillo I (2003) Colloid Surface A 225:153-160 